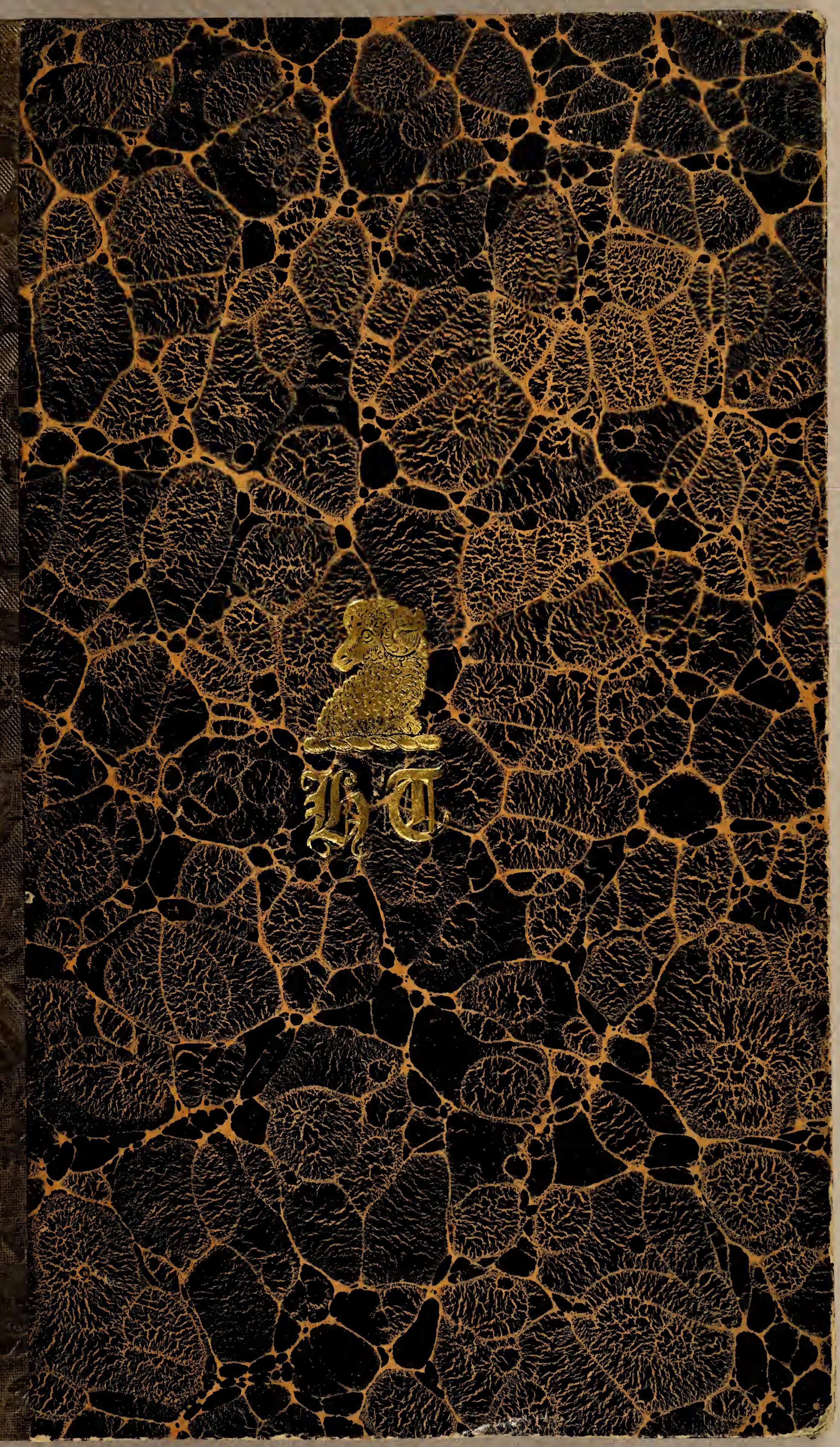




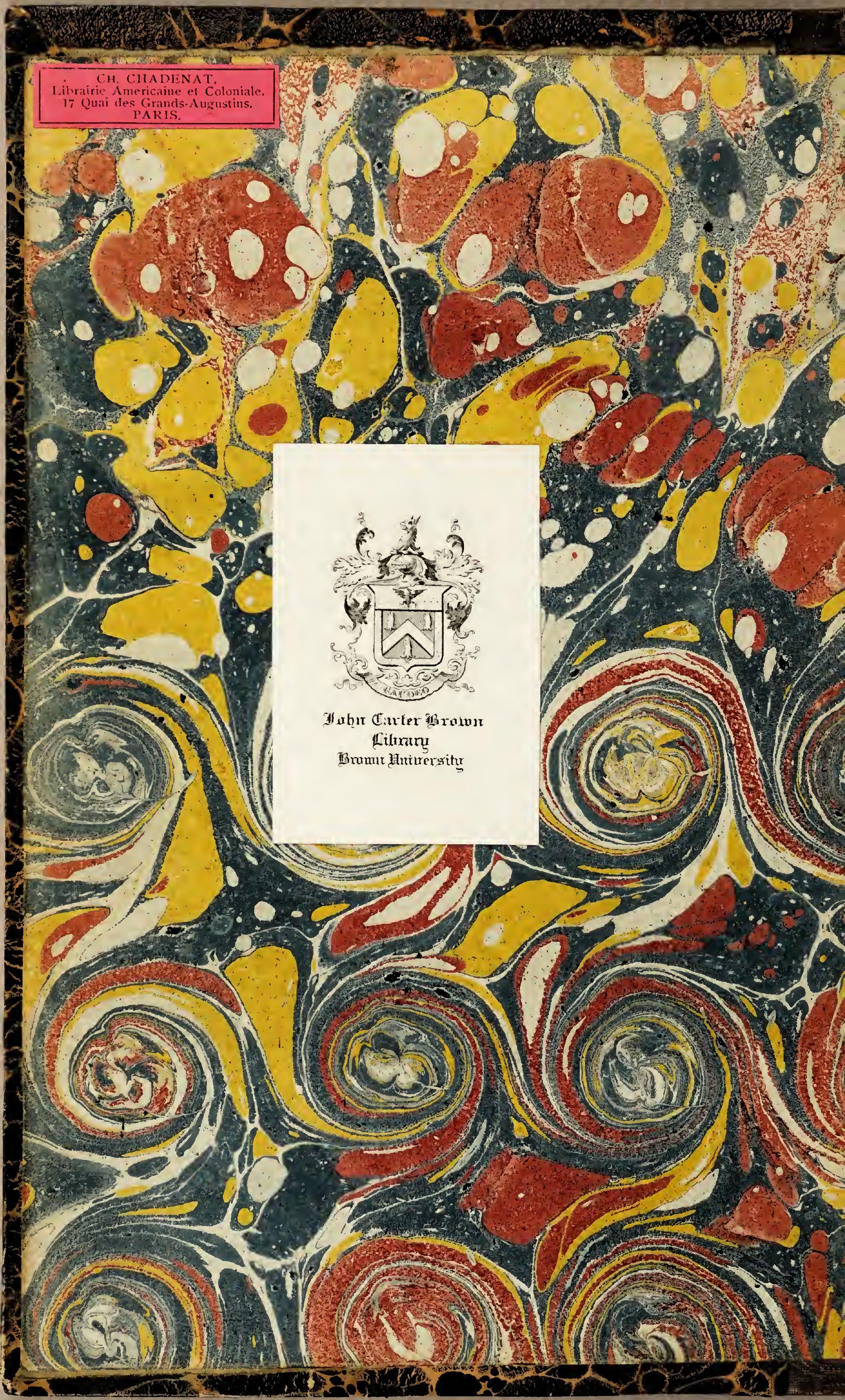




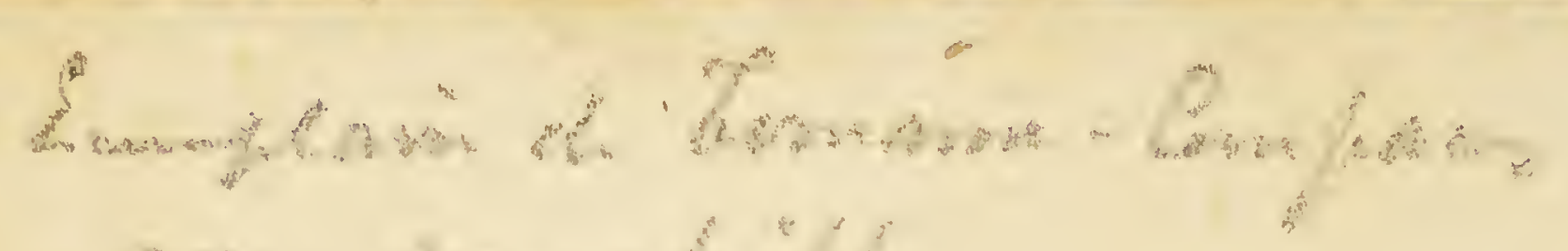

Ain.

che nom attis.

$4860^{2}$

B 



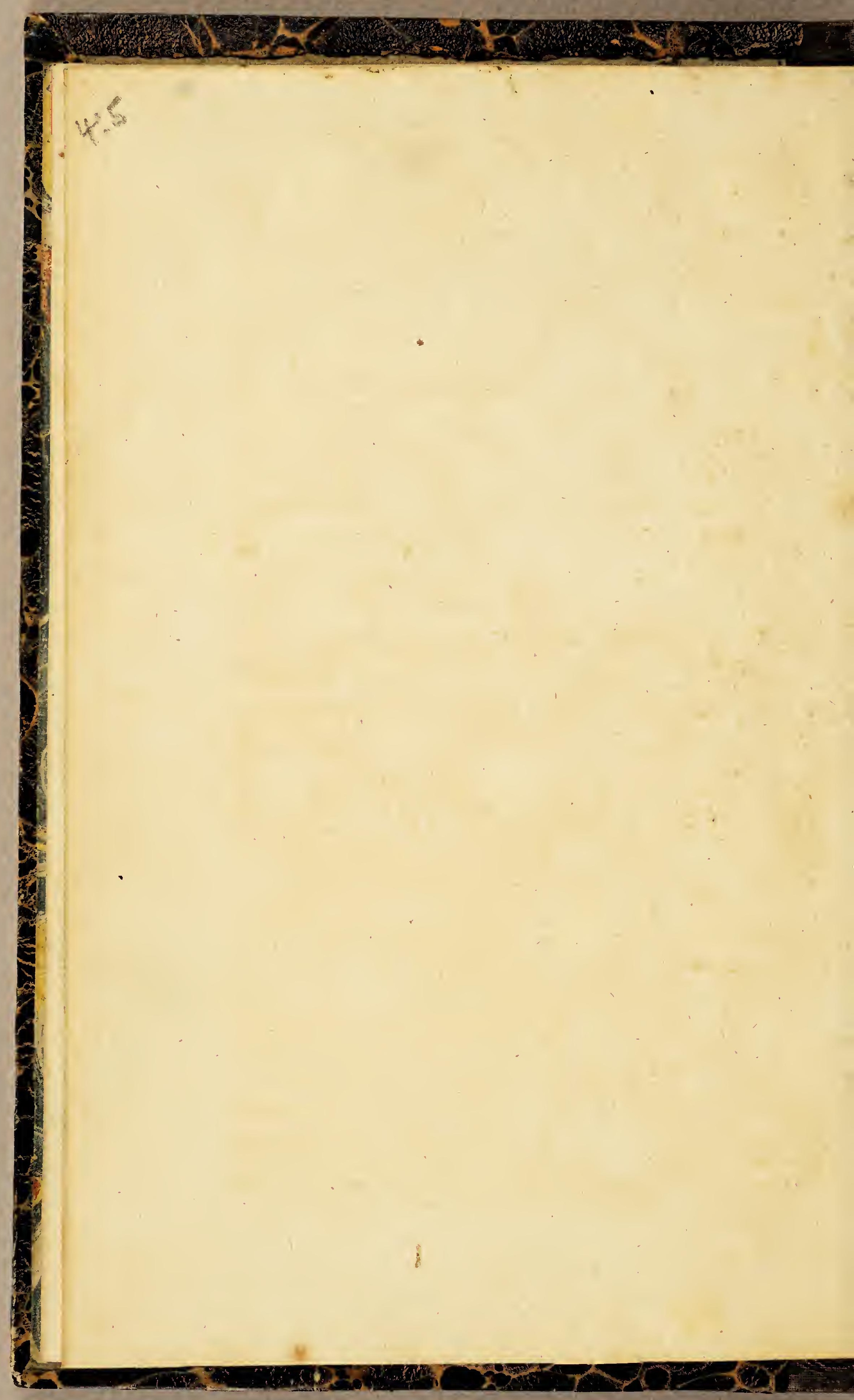




\section{LETTRE DE M.D.L.C.}

\section{A $M^{* * *}$.}

SUR le fort des Afronomes qui ont eu part aux dernieres mefures de la terre, depuis 2735.

LETTRE DE M. GODIN DES ODONAIS, E l'aventure tragiaue de Madame Godin dans Son voyage de la province de Quito, à Cayenne, par le fuewe des Anazones. A Etouilly, près Ham, ein Picarali, $2001 \%$. 1773 : $\checkmark$

o us vous êtes intéreflé, Monf́leur, aux rravaux de l'Académie des Sciences pour la mefure de la terre, \& vous êtes curieux de favoir le fort de tous ceux qui ont eu part à cer ouvrage dans des voyages au-delà des mers, depuis I735. Te pourrois vous répondre par ce vers de Virgile:

Apparent rari nantes in gurgite vafto.

Dans cette vâfe mer, échappés aui nauffrage,

On voit quelques nochers fe fawver à la nage.

Nous partîmes de la Rochelle au mois de Mai 1735 , munis des palle-ports de Sa Majefté Catholique le Roi Philippe I, pour aller mefurer les degrés voifins de l'équateur dans fes Etats de l'Amérique méridionale. Nous étions rrois Académiciens, M. Godin, M. 


\section{(2)}

Bouguer \& moi. Nous avions pour adjoints M. Jofeph de Juffieu, Doteur-Régent de la Faculté de Paris, frere des deux Académiciens, \& qui fut reçu à l'Académie pendant fon abfence ; M. Séniergues, Chirurgienn ; \& pour nous aider dans nos opérations, $M$. Verguin, Ingénieur de la Marine, M. de Morainville, Deffinateur pour l'Hiftoire naturelle, M. Couplet, neveu de l'Académicien; M.Goain des Odonais, qui fera le principal fujet de cette lettre, \& le fieur Hugo, Horloger, Ingénieur en inftrumens de mathématique; nous nous joignîmes, à Carthagene d'A mérique, à deux Lieutenans de vaiffeaux Efpagnols, nonmés par la Cour de Madrid, pour affifter à nos obfervations.

L'année fuivante M. de Mauperzuis, chargé d'aller mefurer les degrés du méridien fous le cercle polaire arctique, s'embarqua à Rouen avec MM. Clairaut, Camus \& le Monnier le cadet, Académiciens, M l'Abbé Outhier, M. Celfucus, Aftronome Suédois, \& quelques autres aides.

En r751, M. l'Abbé de la Caille, Académicien, partit pour le Cap de Bonne-Efpérance, où le moindre de fes travaux fut la mefure de deux degrés du méridien.

Des cinq voyageurs qui ont vu le cercle polaire, il ne refte que M. le Moñzier. L'Abbé de la Caille qui fit feul le voyage du Cap, \& dont la fanté paroiffoit à toute épreuve, de 


\section{(3)}

tetour à Paris, a été la vitime de fon zèle aftronomique, en $176_{2} ; \&$ unAcadémicien(I) plus jeune que lui, qui l'avoir pris pour modèle, a eu depuis le même fort en Californic en 1769 .

Parmi mes compagnons de voyage ì l'équateur, M. Couplet, le plus robufte, \& l'un des plus jeunes, à peine arrivé à Quito, fut emporté en trois jours par une fievre maligne. J'ai rendu compte ailleurs de la fin tragique de notie Chirurgien (2). M. Bouguer eft mort d'un abcès au foie en 1758 ; M. Godin, qui avoit paffé au fervice d'Efpagne, où il ćtoit Directeur de l'Académie des Gardes de la Márinè̀ Cadix, plus jeune que M. Bouguer, ne lui a furvécu que deux ans; $M$. de Morainyille, refié dans la province de Quito, s'eft tué en tombant d'un échafaud d'une Eglife qu'il bâtiffoità Cicalpa, près la ville de Riobamba.II y a plus de quinze ans que je n'ai de nouvelles directes du fieur Hugo qui s'eft marié à Quito. Je ne parle point ici de plufieurs de nos gers, tant blancs que noirs, péris dans le cours du voyage, deux defquels de mort violente.

Le Commandeur Don George Juan, l'anm cien des deux Officiers Efpagnols nos adjoines,

(1) M. l'Abbé Chappe'd'Auteroche, mort en Californie quelques jours après fon obfervation du paffage de Venus fur le foleil en 1769 .

(2) Lettre fur l'émente populaire de Cuenca, Paris 7449

$A$ ij 


\section{(4)}

Capitaine de vaificaux du Roia fon retour,puis Commandant des Gardes de ha Marine d'Efpagne, Chef d'efcadre \& Ambafadeur à Maroc, plus jeune gue la plupart de nous tous, vient de mourira Madrid dune apoplexie. Le DrJofeph de Ju/fzeu, long-tems retenu par l'Audience royale de Quito a caufe de fa profeffion, \& depuis par le Vice-Roi de Lima, eft de retour à Paris depuis deux ans; il a perdu la mémoire conme autrefois le célebre Dom Mabillon, qui la reconvia depuis. M. de Jufferu n'a pas eu le même bonheur; \& je no fais fr lui \& moi pouvons ì nous deur, être comptés pour un individu vivant. Une furdité qui a com. mencé en Amérique ef devenue exceffive, \& depuis cinq ans j'ai perdu la fenfibilité externe dans toutes les parties inféricures, dont je ne fens l'exiftence que par des douleurs internes dans les changemens de tems. Ainfi, des onze voyageurs de la zone tomide, fans parler des domeftiques, on ne doit compter pour exiftans aujourd'hui que M. Verguinn, Ingénieur de Marine à Toulon, Don Antonio de Ulloa, Chef d'cicadre dans la Marine d'Efpagne, ancien Gouverneur de la Louifianne (encore ne font-ils nil l'un ni l'autre exempts d'infirmités) \& M. Godin des Odonais quil vient d'arriver à Paris après trent-huit ans d'abfence, \& qui va me donner matiere à vous entretenir. J'ai reça de lui, au mois d'Août dernier, la lettre fuivante, fur les inftances que je lui avois faites, 


\section{(5)}

de me donne: une relation du voyage de fon époufe que j’ai connue dès fon enfance, 总 des avantures de laquelle il ne m"étoitparvenu que des bruits vagues. Je crois ne pouvoir micux faire que de vous envoyer une copic de la lettre de M. des Odonaís. Vous verrez ce que peut ic courage \& la conftance. Il n'y a pont d'ame qui ne fe fente attendrie au récit de l'horrible aventure d'une femme aimable élevée dans l'aifance, qui, par une fuite d'événemens audeflus de laprudence humaine, fe trouve tranfportée dans des bois impénétrables, habités par des bêtes féroces \& des repriles dangereux, expofće à toutes les horreurs de la faim, de la foif \& de la fatigue, qui erre dans ce défert pendane plufieurs jours, après avoir vî périr fept: perfonnes, \& qui échappe feule à rous cos. dangers, dune maniere qui tient du prodige. Vous verrez enfin tout ce que doit M. Godin à la munificence de Sa Miajellé Porrugaife, \& anx Oficiers chargés de fes ordres.

Sur les repréfentations de M. Godin, le Minitte bienfaifant ( 1 ), qui a dans fon département les ficadénies, vient de lui obtenir de Sa Majefté une penfion, qu'il a bien méricée par fon aèle \& fes travaux pendant nos opérations, \& par un fi long exil de fa patrie vers. loquelle il n'a cefé de: couner hes regards.

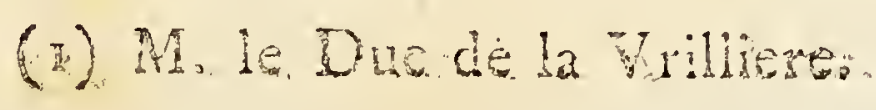

$$
\text { A }
$$


$L E T T R E$

D E

\section{GODIN DES ODONAIS,}

A M. DE LA CONDAMINE.

Saint-Amand, Berry, 28 Juillet 1773 a

\section{Monsieur,}

Vous me demandez une relation du voyage de mon époufe par le fleuve des Amazones, la même. route que j’ai fuivie après vous. Les bruzs confus. qui vous font parvenus des dangers auxquels elle s'eft vue expofée, \& dont elle fenle de huir perfonnes eft échapèe, augmentent votre çuriofité. J'avois réfolu de n'en parler jamais, tant le fouvenir m'en eft douloureux; mais le titre de votre ancien compagnon de voyage, titre dont je me fais honneur, la part que voars prenez à ce qui nous regarde, \&rlesmarques d'amitié que vons me clonez, se me permettent pas de refufer de vous fatisfaire.

Nous débarquâmes à la Rochelle le 26 Intiz dero nier $(1773)$, après foixante-cinqjours de traverfée, 


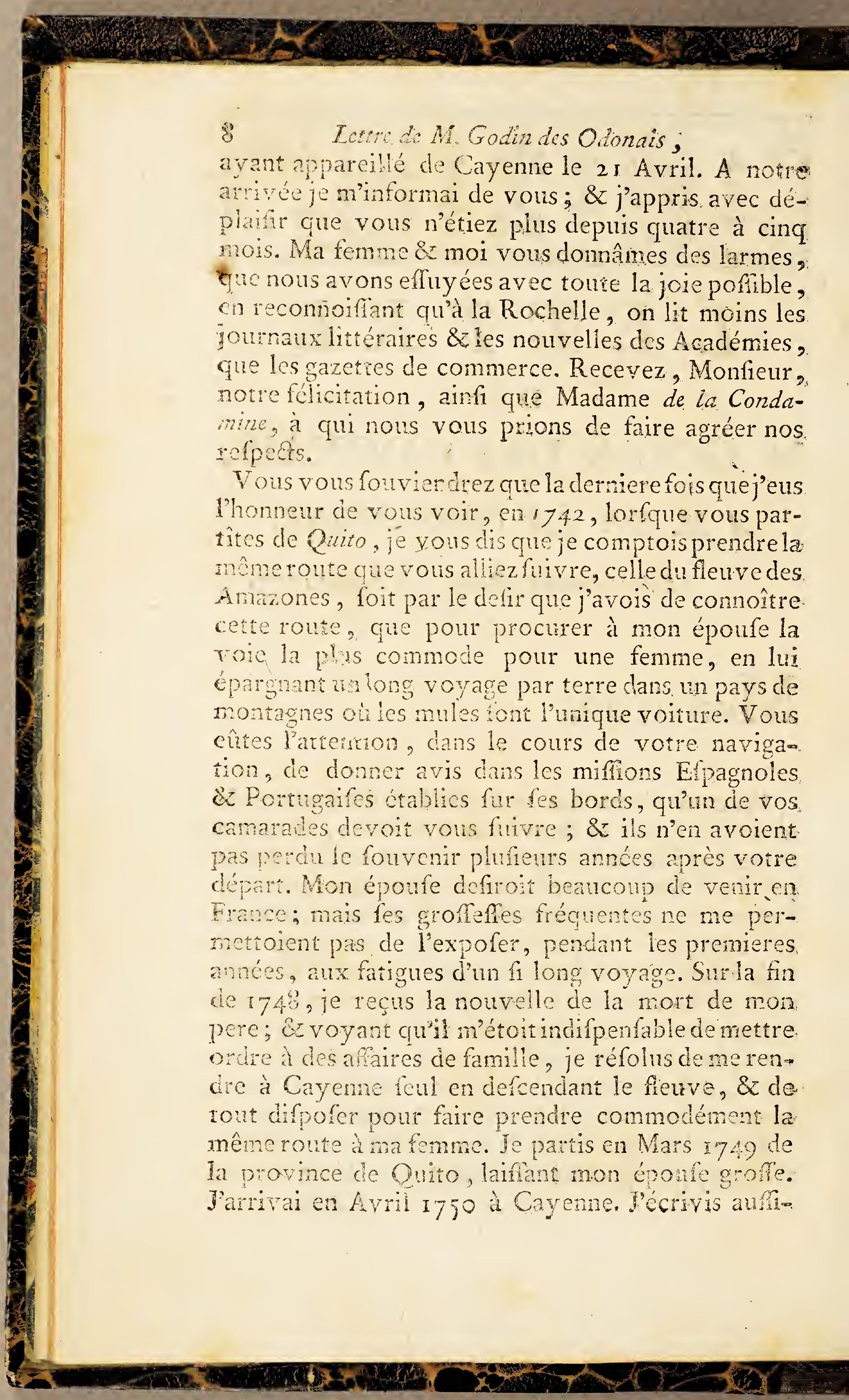




\section{a H. de la Condamine.}

tôt à M. Rouillé, alors Minifre de la Marine, \& le priai de mobtenir des paffe-ports \& des recommandations de la Cour de Portugal, pour remonter l'Amazone, allerchercher ma fanille, \& l'amener paia la même route. Un autre que vous, Monfieur, feroit furpris que jaie entrepris fi leftement un voyage de quinze cents lieues, uniquement pour en préparer un autre; mais vous favez que dans ce pays-1d les voyages exigent moins d'appareil quén Europe. Ceux que javois faits depuis douze ans, cn reconnoiflant le terrein de la méridienne de Quiro, er pofant des ignaux fur les plus hautes montagnes, en allant \& revenant de Carihagene, mavoien agierri. Je profitai de cette occafion pour envoyer piufeurs morceaux d'hiftoire naturelle au jardin du cabinet du Roi, entre autres la graine de falfe-pareille, la butua cians fes cing efpeces, \& une grammaire imprimée à Lima, de la langue des incas, dont je faifois prélent à M. de Buffon, de qui je n'ai reçu aucune réponfe. Par celle dont M. Rotillém monora, jappris que Sa Majefté trouvoit bon que MM. les Gouverneur \&z Intendant de Cayenne me donnafient des recommandations pour le gouvernement du Parin. Je vous écrivis ators, Monfeur; $\mathbb{E}$. vous en̂tes la bonté de follicicer mes paffe-ports. Vous menvoyâtes aufí une letre de recomman. dation de M. le Commandeur de la Cerda, Minifre de Portugal en France, pour le Gouverneur du Para, \& une letre de M. ${ }^{3}$ Abbé de la Ville qui vous marquoit que mes paffe-ports étorent expédiés a Lirbonne, \& envoyés au Para. J'en denandai des nouvelles au Gouverneur de cetre place, qui me répondit n'en avoir aucune connoifance. Je répétai nes. letres à M. Rozilié, qui ne fe trouva plis dans le minifere. Depuis ce tems j'ai follicité quatre, cinq $\&$ fr fois chaque année pour avoir les pafie-pors, \& toujours infugueurement. Plufenis de nes 
xo

Leitre de M. Gadin des Odonais;

Iettres ont été perdues ou interceptées pendant la guerre. Je n'en puis douter, puifque vous avez cefie de recevoir les miennes, qucique j'aie continué de yous écrire. Enfin ayant oui dire que M. le Comte d'Hérouville avoit la confiance de M. Ie Duc de ChoiSeul, je m'avifai, en 1765 , d'écrire au premier fans avoir l'honneur d'en être connu. Je lui marquois en peu de mots qui j'étois, \& le fuppliois d'intercéder pour moi auprès de M. de Choifeul au fujet des paffeports. Je ne puis attribuer qu'aux bontés de ce $S e^{i-}$ gneur le fuccès de ma démarche, puifque le dixieme mois, à compter de la date de ma lettre à M. le Comte d'Hérouville, je vis arriver à Cayenne une galiote. pontée, armée au Para par ordre du Roi de Porti. gal, avec un équipage de trente rameurs, \& commandée par un Capitaine de la garnifón de Para, chargé de m'y conduire, \& du Para, cn remontant le. fleuve, jufqu'au premier établiffement Efpagnol, pour y attendre mon retour \& me ramener à Cayenne avec ma famille: le tout aux frais de Sa Majefté Très-Fidèle : gérérofté vraiment royale \& peucommune même parmi les Souverains. Nous pars. times de Cayenne les derniers jours de Novembre. 1765 , pour aller prendre mes effets à Oyapok (I), où je réfidois. Je tombai malade, \& même affez dangereufement. M. de Rebello, Chevalier de l'Ordre de Chrift, \& Commandant de la galiotte, eut la complaifance de m'attendre fix femaines. Voyant enfin que je n'étois pas en état de m'embarquer, \& craignant d'abufer de la patience de cet Officier, je le priai de fe mettre en chemin, en me permettant d'embarquer quelqu'un, que je chargerois de mes. lettres \& de tenir ma place pour foigner ma famille au retour. Je jettai les yeux fur Trifand'Oa

(1) Fort fir la riviere de même nom à trente lienes aw Sud de la vilie de Cayenne 


\section{'à $M$. de la Condamine:}

reasaval que je connoiffois depuis long-tems, que je crus propre à remplir mes vues. Le paquet dont je le chargeois contenoit des ordres du Pere Général des Jéfuites au Provincial de Quito \& au Supérieur des Mifíons de Mainas, de faire fournir les cạnots \& équipages néceffaires pour le voyage de mon époufe. La commiffion dont je chargeois Triftan étoit uniquement de porter ces lettres au Supérieur réfident à la Laguna, chef-lieu des miffions Efpagnoles de Mainas, que je priois de faire tenir mes lettres à Riobamba, afin que mon époufe fût avertie de l'armement fait par ordre du Roi de Portugal, à la recommandation du Roi de France, sour la conduire à Cayenne. Triftan n'avoit d'autre chofe à faire, finon d'attendre à la Laguna la réponfe de Riobamba. Il partit du pofte;'O'Oyapok fur le bâtiment Portugais le 24 Janvier 1766 . Il arriva à Loreto, premier établiffement Efpagnol dans le. haut du fleuve au mois de Juillet ou d'Août de la même année. Loreto eft une miffion nouvellement fondée au-deffous de celle de Pévas, \& qui ne l'étoit pas encore lorfque vous defcendites la riviere en I 743, ni même lorfque je fuivis la même route en I 749 , non plus que la miffion de Tavatinga que les Portugais ont auffi depuis fondée au-deffus de celle de San-Pablo, qui étoit leur dernier établiffement en remontant. Pour mieux entendre ceci, it feroit bon d'avoir fous les yeux la carte que vous avez levée du cours de l'Amazone, ou celle de la province de Quito, inférée dans votre journal hiftorique du voyage à l'équateur. L'Officier Portugais, M. de Rebello, après avoir débarqué Trifan à Loréto, revint à Tavatinga, fuivant les ordres qu'il avoit reçus d'y attendre l'arrivée de Mad. Godin; $\& \varepsilon$ Triftan, au lieu de fe rendre à la Laguna, chef-lieı des miffions Efpagnoles, \& d'y remettre mes lettres au Supérieur, ayant rencontré à Loréto un mifion. 


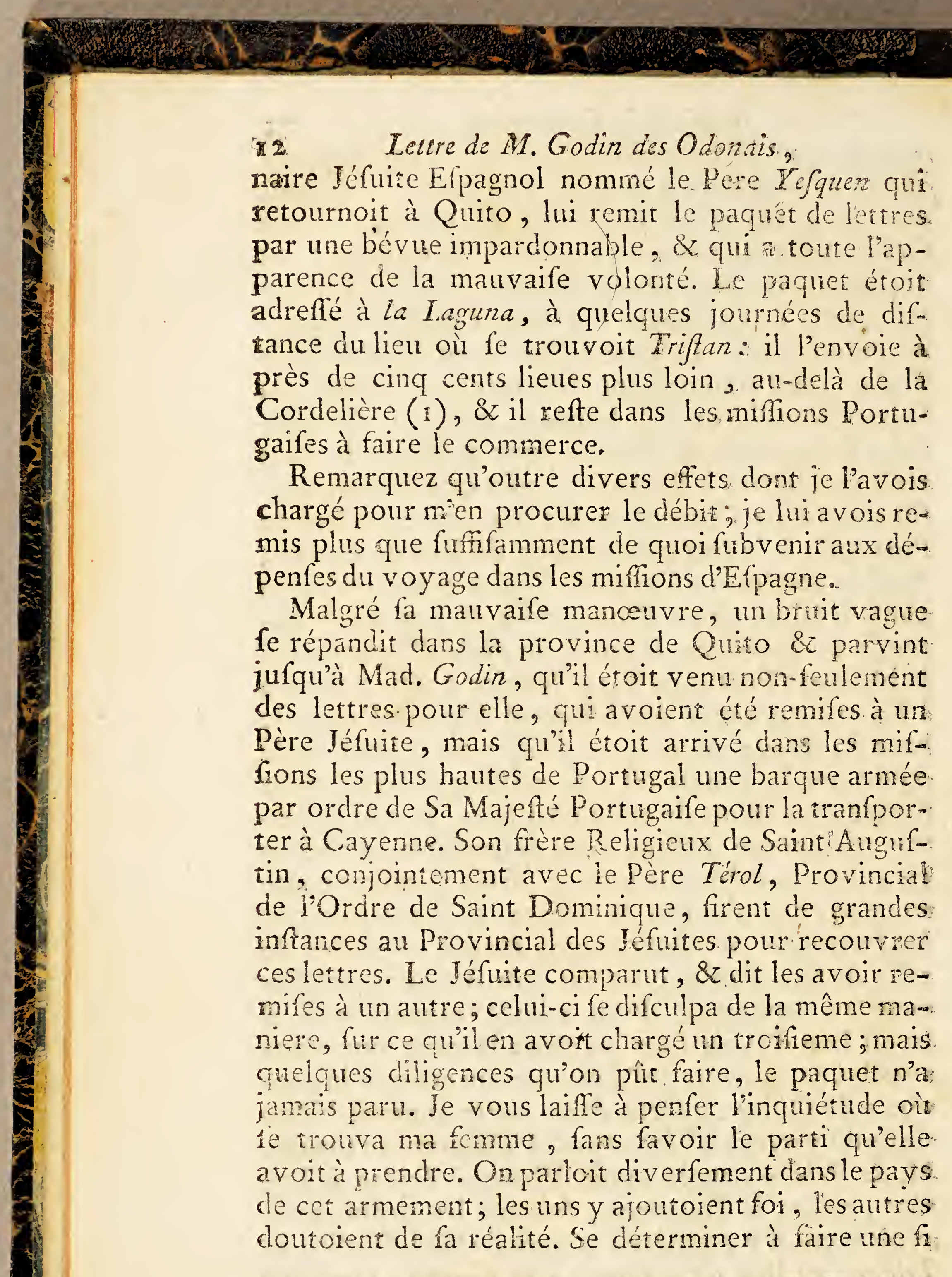

42

Letere de M. Godin des Odonats, naire Jefuice Elpagnol nomne le pere Iefauen qui retournoit à Quito, lui remir le paquét de lettres. par une bévue impardonnable, \& qui a toute l'apparence de la mauvaife volonté. Le paquế étoit adreffé à la Laguna, à quelques journées de diftance du lieu où fe trouvoit Triftan: il l'envoie à près de cinq cents lieues plus loin, au-delà de la Cordelière (I), \& il refte dans les, miffions Portugaifes à faire le commerce.

Remarquez qu'outre divers effets dont je lavois charge pour men procurer le débit j je lui avois red mis plus que fuffifamment de quoi fubvenir aux dépentes du voyage dans les milions d'Etpagne.

e répandit dans la province de Quito \& parvint jufqu'à Mad. Godin, qu'il étoit venu non-feulement des lettres pour elle, qui avoient été remifes à un Pere Jéfuite, mais qu'il étoit arrivé dans les miffrons les plus hautes de Portugal une barque armée par ordre de Sa Majefté Portugaife pour la tranfpor. ter à Cayenne. Son frère Religieux de Saint Auguftin, conjointement avec le Père Térol, Provincial de l'Ordre de Saint Dominique, firent de grandes infances au Provincial des Jéfuites pour recouver ces lettres. Le Jéfuite comparut, \& dit les avoir remifes à un autre; celui-ci fe difculpa de la même maniere, fur ce quil en avoft chargé un troifieme; mais guelques diligences qu'on put faire, le paquet n'a: jamais paru. Je vous laiffe à penfer linquiétude oit le irouva ma fcmme, fans favoir le parti qu'elle avoit à prendre. On parlcit diverfement dans le pays de cet armement; les uns y ajoutoient foi, les autres doutoien de fa réalité. Se déterminer à faire une fi

(1) La chaine des hautes montagnes connues fous le nom de Corleliere des Andes, qui traverfe toute l'Amérigne meridionale du Nord an Sud. 


\section{à $M$. de la Condamine.}

longue route, arranger en conféquence fes affaires domefiques, vendreles meubles d'une maifon, fans aucune certitude; c'étoit mettre tout au hafard. Enfin, pour favoir à quoi s'en tenir, Mad. Godin réfolut d'envoyer aux miffions un Nègre d'une fidélité éprouvée. Le Nègre part avec quelques Indiens de compagnie; \&2 après avoir fait une partie du chemin, il eft arrêté \& obligé de revenir chez fa mầtreffe, qui l'expédia une feconde fois avec de nouveaux ordres \& de plus grandes précautions. Le Nègre retourne, furmonte les obftacles, arrive à Loréto, voit Triftaz \& lui parle; il revient avec la nouvelle que l'armenent du Roi de Portugal étoit certain, \& que Triftan ćtoit à Loréto. Madame Godin fe détermina pours lors à fe mettre en chemin; elle vendit ce qu'elle put de fes meubles, laifla le refte, ainfi que fa maíon de Riobamba, le jardin \& terres de Guaflen ; un autre bien entre Galté \& Maguazo à fon beau-irere. On peut juger du long tems qui s'écoula depuis le mois de Septembre 1766 que les lettres furent remifes au Jéfuite, par le tems qu'éxigerent le voyage de ce Pere à Quito, les recherches pour retrouver le paquet paffé de main en main, l'éclairciffement des bruits répandus cians la province de Quito \& parvenus à Madame Godin à Riobamba, fes incertitudes, les deux voyages de fon Nègre à Loréto, fon rétour à Riobamba, la ventełdes effets d'une maifon \& les préparatifs d'un fi long voyage; aufin ne put-elle partir deRiobamba, quarante lieues au Sud de Quito, que le premier Octobre 1769 .

Le bruit de l'armement Portugais s'étoit entendu jufqu’à Guayaquil \& fur les bords de la mer du Sud, puifque le fieurR. foi-difant Médecin François, qui revenoit du haut Pérou \& alloit à Panama ou PortoBelo chercher un embarquement, pour paffer à Saint-Domingue ou à la Martinique, ou du moins 


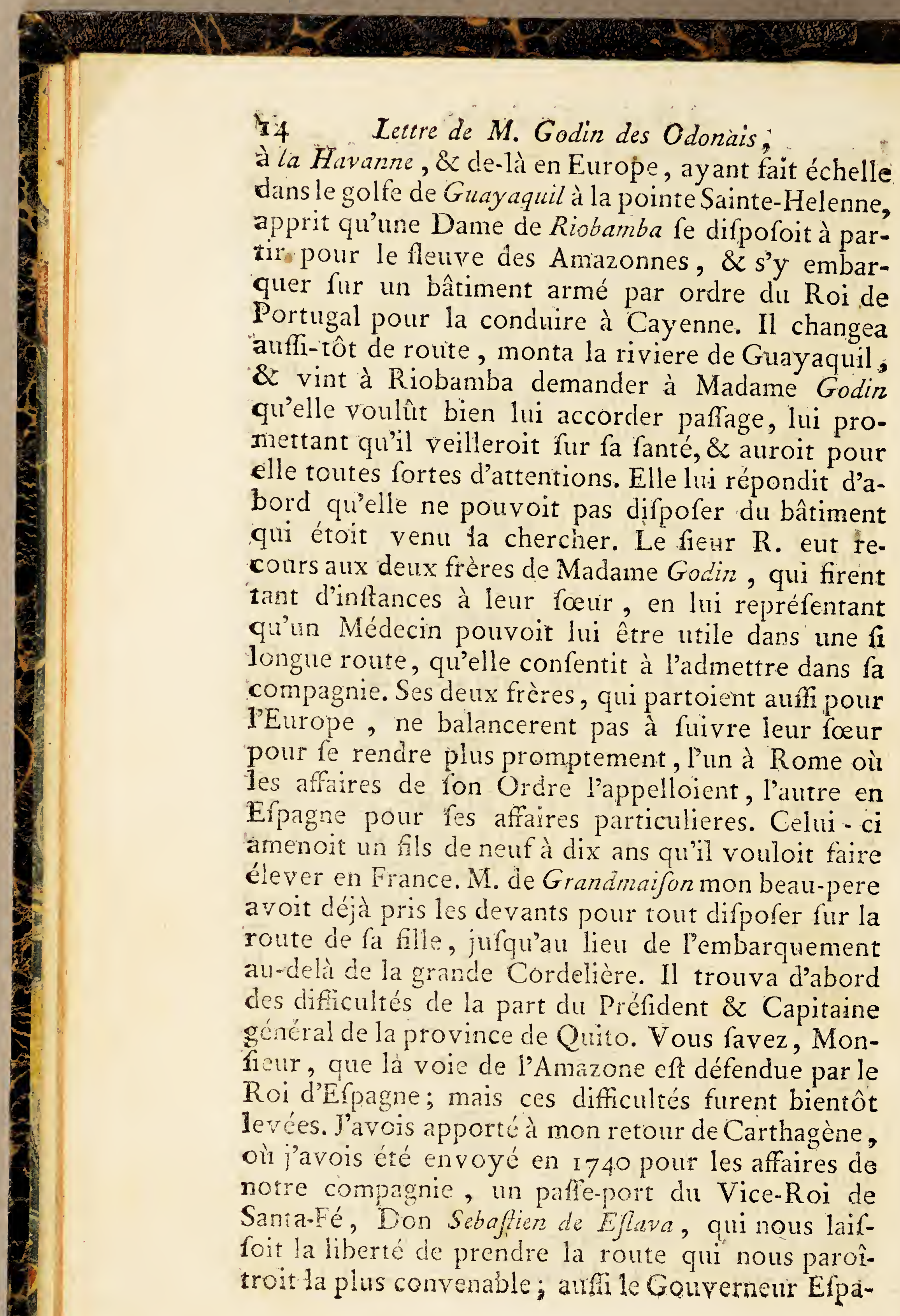




\section{'à M. de la Condamine.}

gnol de la province de Maynas \& d'Omagnas, prévenu de l'arrivée de mon époufe, eut la politeffe d'envoyer à fa rencontre un canot avec des rafraîchiffemens, comme fruits, laitage, \&c. qui l'atteignit à peu de diftance de la peuplade d'Omagnas; mais quelles traverfes, quelles höreurs devoient précéder cet heureux moment! Elle partit de Riobamba, lieu de fa réfidence, avec fon efcorte, le premier Octobre 1769 ; ils arriverent à Canclos lieu de l'embarquement fur la petite riviere de Bobonafa qui tombe dans celle de Paftafa, \& celle-ci dans l'Amazone. M. de Grandmaifon qui les avoit précédés d'environ un mois, avoit trouvéle village de Canélos peuplé de fes habitans, \& s'étoit auffi-tôt embarqué pour continuer fa route $\&$ prévenir des équipages à l'arrivée de fa fille dans tous les lieux de fon paffage. Comme il la favoit bien accompagnée de fes frères, d'un Médecin, de fon Nègre \& de trois domeftiques Mulâtreffes ou Indienres, il avoit continué fa route jufqu'aux miffions Portugaifes. Dans cet intervalle une épidémie de petite vérole, maladie que les Européens ont portée en Amérique, $\&$ plus funefte aux Indiens que la pefte, qu'ils ne connoiffent pas, ne l'eft au levant, avoit fait déferter tous les habitans du village de Canélos qui avoient vu mourir ceux que ce mal avoit attaqué les premiers; les autres s'étoient difperfés au loin dans les bois, où chacun d'eux a voit fon abatis; c'eft leur maifon de campagne. Ma femme étoit partie avec une efcorte de trente-un Indiens poarr la porter elle \& fon bagage. Vous favez que ce chemin, le même qu'avoit pris Don Pedro Maldonado, auffi parti de Riobamba pour fe rendre à la Laguna, où vous vous étiez donné rendez-vous; que ce chemin, dis-je, n'eft pas praticable même pour des mulets; que les hommes en état de marcher le font d pied, \& que les autrès fe font porter. Les Indiens. 
que Madame Godin avoit amenés \& qui étoient payés d'avance, firivant la mauvaife coutumé du pays, à laquelle la méfiance, quelquefois bien fondée, de ces malheureux, a donné lieu, à pèine arrivés à Canélos, retournent fur leurs pas, foit par la crainte du mauvais air, foit de peur qu'on ne les obligeât de s'embarquer, eux qui n'avoient jamais vu un canot que de loin. Il ne faut pas même chercher de $f 1$ bonnes raifons pour leur défertion; vous favez, Monfieur, combien de fois ils nous ont abandonnés fur nos montagnes, fans le moindre prétexte, pendant le cours de nos opérations. Quel parti pouvoit prendre ma femme en cette circonftance? Quand il lui êt été poffible de rebrouffer chemin, le defir d'alier joindre certe barque difpofée pour la recevoir par ordre de deux Souverains, celui de revoir un époux après vingt ans d'abfence, hii firent braver tous les obftacles dans l'extrêmitê oì elle fe voyoit réduite.

Il ne reftoit dans le village que deux Indiens échap: pés à la contagion; ils étoient fans canot. Ils promirent de lui en faire un, \& de la conduire à la mifion d'Andoas, environ douze journées plus bas en dercendant la riviere de Bobonaza, diftance qu'ón peut eftimer de cent quarante à cent cinquante lieues; elle les paya d'avance; le canot achevé ils partent tous de Canélos, ils naviguent deux jours; on s'arrête pour paffer la nuit. Le lendemain matin les deux In diens avoient difparu; la troupe infortunée fe rembarque fans guide, \& la premiere journée fe paffe fans accident. Le lendemain, fur le midi, ils rencontrent un canot arrêté dans un petit port voifin d'un carbet (I); ils trouvent un Indien convalefcent

(1) C'ett le nom que l'on donne dans nos coloniez des intes \& en Canada aux feuillées qui fervent d'habitations aut farvages \& d'abriaux voyageurs; les Efpagnols leur donrent le nom de Ranche. 
qui confentit d'aller avec eux, \& de tenir le gouvernail. Le troifième jour, voulant ramaffer le chapeau du fieur R... qui étoit tombé à l'eau, l'Indien y tombe lui-même; il n'a pas la force de gagner. le bord \& fe noie. Voilà le canot dénué de gouvernail , \& conduit par des gens qui ignoroient la moindre manouvre; aufí fut-il bientôt inondé; ce qui les obligea de mettre à terre \& d'y faire un carbet. Ils n'étoient plus qu'à cinq ou fix journées d'Andoas. Le fieur $R . . .$. s'offrit à y aller, \& partit avec ur autre François de fa compagnie, \& le fidele Nègre de Madame Godin qu'elle leur donna pour les aider; le fieur R.... eut grand foin d'emporter fes effets. J'ai reproché depuis à mon époufe de n'avoir pas envoyé auffi un de fes frères avec le fieur. $R . .$. , chercher du fecours à Andoas; elle m'a répondu que ni l'un ni l'autre n'avcient voulu fe rembarquer dans le canot après l'accident qui leur étoit arrivé. Le fieur $R$. . . avoit promis, en partant, i Madame Godin \& à fes freres, que fous quinze jours ils recevroient un canot \& des Indiens. Au lieu de quinze, ils en attendirent vingt-cinq, \& ayant perdu l'efpérance à cet égard, ils firent un radeau fur lequel ils fe mirent avec quelques vivres $\&$ effets. Ce radeau mal conduit auffi, heurta contre une branche fubmergée \& tourna : effets perdus, \& tout le monde à l'eau. Períonne ne périt graces au peu de largeur de la rivière en cet endroit. Madame Godin, après avoir plongé deux fois, fut fauvée par fes frères. Réduits à une fituation plus trifte encore que la première, ils réfolurent tous de fuivre à pied le bord de la rivière. Quelle entreprife: Vous favez, Monfieur, que les bords de ces rivières font garnis d'un bois fourré d'herbes, de lianes $\&$ d'arbuftes, où l'on ne peut fe faire jour que la ferpe à la main, en perdant beaucoup de tems. Ils retour nent aे leur carbet 2 prennent les vivres qu'ils $\mathrm{y}$ 


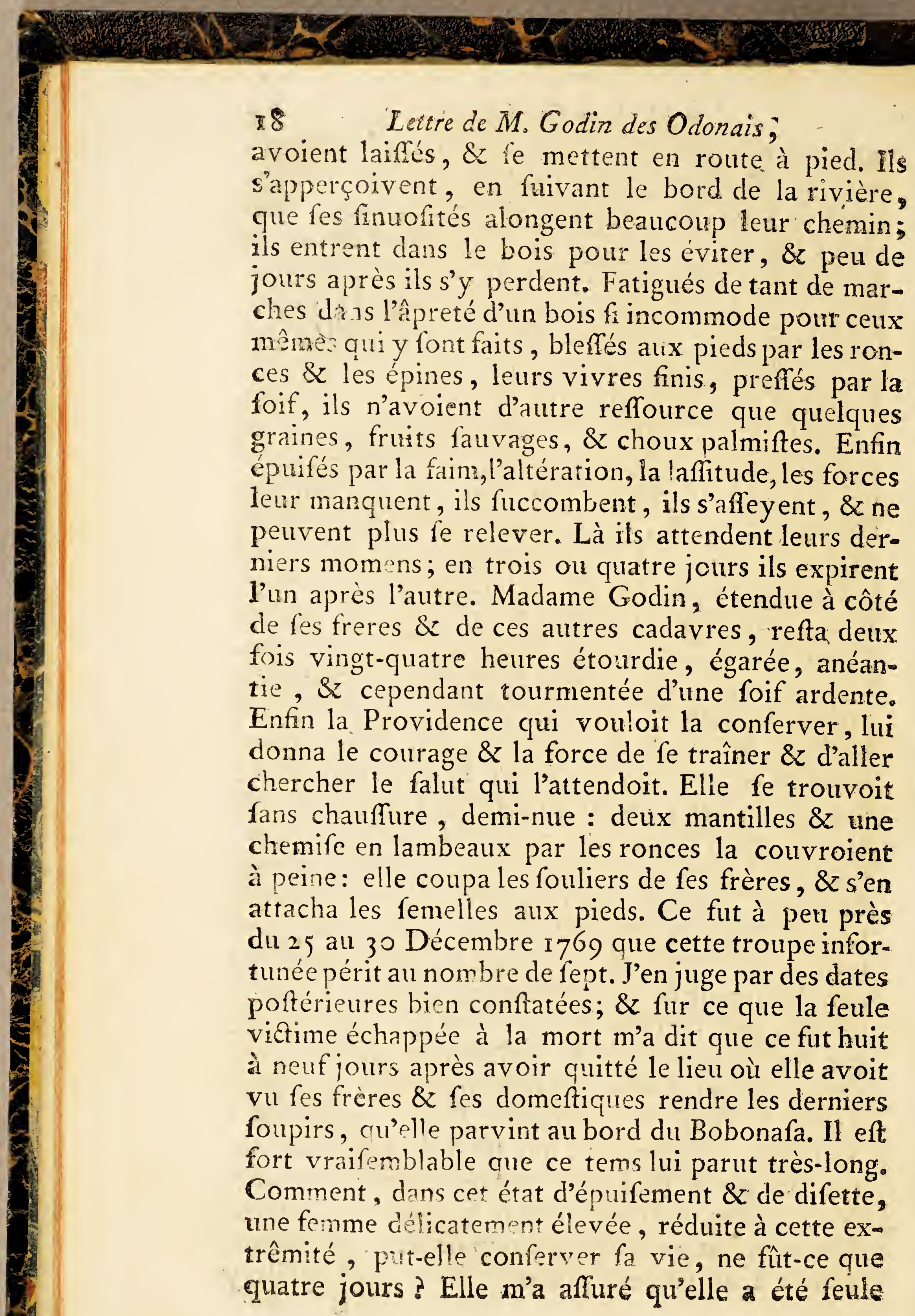




\section{at M. de la Condaminte}

dans le bois dix jours, dont deux à côté de fes frères morts, attendant elle-même fon dernier moment; $\&$ les autres huit à fe trainer errant cà \& là. Le fouvenir du long \& affreux fpectacle dont elle avoit. été témoin, l'horreur de la folitude \&. de la nuit dans un défert, la frayeur de la mort toujolirs préfente à fes yeux, fraycur que chaque inftant devoit redoubler, firent fur elle une telle impreffion que fes cheveux blanchirent. Le deuxieme jour de fa marche, qui ne pouvoit pas être confidérable, elle trouva de l'eau, \& les jours fuivans quelques fruits fauvages \& quelques œufs verds qu'elle ne connoiffoit pas, mais que j'ai reconnus par la defcription qu'elle m'en a faite pour des oufs d'une efpece de perdrix (1). A peine elle pouvoit avaler, tan l'oezophage s'étoit retréci par la privation des alimens. Ceux que le hafard lui faifoit rencontrer fuffirent pour fubftenter fon fquelette. Il étoit tems que le fecours qui lui étoit réfervé parût.

Si vous lifiez dans un roman qu'une femme délicate, accoutumée a jouir de toures les commodités de la vie, précipitée dans une riviere, retirée à demi noyée, s'enfonce dans un bois elle huirième, fans route, \& y marche plufieurs femaines, fe perd; fouffre la faim, la roif, la fatigue jurqu’à l'épuifement, voit expirer fes deux frères beaucoup plus robuftes qu'elle, un neveu à peine forti de l'enfance, trois jeunes femmes, fes domeftiques, un jeune valet du mèdecin qui avoit pris les devants; qu'elle furvit à cette cataftrophe; que reftée feule deux jours $\&$ deux nuits entre ces cadavres, dans des cantons oit abondent les tigres $\&$ bealicoup de ferpens très-dangereux (2), fans avoir jamais rencontré un

(I) C'eft du moins le nom que donnent les Expagnols a ce gibier affez commun dans les pays chands d'Amérique.

(2) J'ai vu dans ces quarticrs des onces, forte de tigre noin $\mathrm{B}$ ij 
feul de ces animaux; qu'elle fe relève, fe remer en chemin coliverte de lambeaux, errante dans un bois fans route, jufqu'au huitième jour qu'elle fe retrouva fur le bord du Bobonola; vous accuferiez l'auteur du roman de manquer à la vraifemblance; mais un hiftorien ne doit à fon lecteur que la fimple vérité. Elle eft atteftée par les lettres originales que j'ai entre les mains de plufieurs Miffionnaires de l'Amazonne, qui ont pris part à ce trifte événement dont je n'ai eu d'ailleurs que trop de preuves, comme vous le verrez par la fuite de ce récit. Ces malheurs ne feroient point arrivés, fi Trifan n'eût pas été un commiffionnaire infidèle; $f i$, au lieu de s'arrêter à Loréto, il avoit porté mes letires au Supérieur à la Laguna, mon époufe eût trouvé, comme fon pere, le villagede Canélos peuplé d'Indiens, \& un canot prêt pour continuer fa route.

Ce fut donc le huir ou neuvième jour, fuivant le compte deMadame Godin, qu'après avoir quittéle lieu. de la fcène funefte, elle fe retrouva fur les bords dus Bobonofa. A la pointe du jour elle entendit dubruit à environ deux cents pas d'elle. Un premier mouvement de frayeur la fit d'abord fe renfoncer dans le bois; mais faifant reflexion que rien ne pouvoit lui arriver de pis que fon état actuel, \& qu'elle n'avoit par conféquent rien à craindre, elle gagra le bord, \& vit deux Indiens qui pouffoient un canot à l'eau. Il eit d'ufage lorfqu'on met à terre pour faire nuit, d'échouer en tout ou partie les canots, pour éviter les accidens; \& en effet un canot à flot pendant la nuit \& dont l'amarre cafferoit, s'en iroit à la dérive; \& que deviendroient ceux qui dorment

la plus féroce; il y a aufi en ferpens des efpeces les plus venimeufes, telle que le ferpent à fonnette, celui que les ESpagnols nomment Coral, \& le fameux Balalao, quion nomme à Cayenne, Serpent grage, 


\section{à M. de la Condamine:}

tranquillement à terre? Les Indiens apperçurent de leur côté Madame Godin, \& vinrent à elle. Elle les conjura de la conduire à Andoas. Ces Indiens, retirés depuis long-tems de Canelos avec leurs femmes pour fuir la contagion de la petite vérole, venoient d'un abattis qu'ils avoient au loin, \& defendoient à Andoas. Ils reçurent mon époufe avec des. témoignages d'affection, la foignèrent $\&$ la conduifirent à ce village. Elle auroit pu s'y arrêter quelques jours, pour fe repofer, \& l'on peut juger qu'elle en avoit grand befoin, mais indignée du procédé dı Miffionnaire d̀ la merci duquel elle fe trouvoit livrée, \& avec lequel, pour cette raifon même, elle fe vir obligée de diffimuler, elle ne voulut pas prolonger fon féjour à Andoas, \& n'y eût pas même paffé la nuit, fi cela eît dépendu d'elie.

Il veroit d'arriver une grande révolution dans. les miffions de l'Amérique E.fpagnole dépendantes de. Lima, de Quito , de Charcas, \& du Paraguai, deffervies \& fondées par les Jéfuites depuis un \& deux fiecles. Un ordre imprévu de la Cour de Madrid les. avoit expulfés de tous leurs colléges \& de leurs mif. fions. Ils avoient tous été arrêtés, embarqués \& envoyés dans les Etats du Pape. Cet événement n’avoit pas caufé plus de trouble quen'eût fait le changement d'un Vicaire de village. Les Jéfuites avoient été remplacés par des prêtres féculiers. Tel étoit celui qui rempliffoit les fonctions de Mifinonnaire à Andoas, \& dont je cherche à oublier le nom. Madame Godin dénuée de tout, \& ne fachant comment témoigner fa. reconnoifance aux deux Indiens. qui lui avoient fauvé la yie, fe fouvint qu'elle avoit au col, fuivant lufage du pays, deux chaines d'or du poids denviron quatre onces; elle en donna une d̀ chaque Indier, aui crut voir les cieux ouverts; mais le Mifronnaire, en fa préfence même, siempara des deux chaines, \& les remplaca en doi Biij 


\section{2}

\section{Lettre de M. Godin des Odonais,}

nant aux Indiens trois ou quatre aunes de cette grofle toile de coton fort claire, que vous favez qui te fabrique dans le pays, \& qu'on nomme Tucuyo. Ma femme fut 1 irritée de cette inhumanité, qu'elle demanda à l'inftant même un canot $\&$ un équipage, \& partit dès le lendemain pour la Laguna. Une Indienne d'Andoas lui fit un jupon de coton, qu'elle envoya payer dès qu'elle fut arrrivée à la Laguna, \& qu'elle conferve précieufement, ainfi que les femelles des fouliers de fes frères dont elle s'étoit fait des fandales : trifte monument qui m'eft devenu cher ainfi qu'à elle.

Pendant qu'elle erroit dans les bois, fon fidèle Nìgre remontoit la rivière avec les Indiens d'Andoas, qu'il amenoit à fon fecours. Le fieur $R$...., plus occupé de fes affaires perfonnelles que de preffer l'expédition du canot qui devoit rendre la vie à fes bienfaiteurs, à peine arrivé à Andoas, en étoit parti avec fon camarade \& fon bagage, \& s'étoit rendu ì Omaguas. Le Nègre arrivé au carbet où il avoî laiffé fa maitreffe $\&$ fes freres, fuivit leur trace dans les bois, avec les Indiens du canot jufqu’àla rencontre des corps morts déjà infects \& méconnoiffables. A cet afpeer, perfuadés qu'aucunn'avoit échappé à la mort, le Nògre \& les Indiens reprirent le chemin du carbet, recueillirent tout ce gu'on y avoir laiffé, \&x revinrent à Andoas avant que ma femme y fût arrirée. Le Nègre, à qui il ne refoit plus de doute fur la mort de fa mâtrefe, alla trouver le fieur $R$.... à Cmaguas, \& lui remit tous les effets dont il s'étoit chargé. Celui-ci n'jgnoroit pas que M. de Grandmaifon, arrivéa Loréto, $y$ attendoit fes enfans avec impatience. Une lettre de Trifan que jai entre les mains prouve mêmè que non beaupère, informé de l'arrivée du Nègre Tacinn, recommandoit à Trifan de l'aller chercher \& de le lui anener; mais ni Trigan ni ie four $R$. . . ne jugerent 
a M. de la Condamine.

pas à propos de fatisfaire mon beau pere; $\& x$ loin de fe conformer à for defir, le freur...., de fon aur torité, renvoya le Negre à Quito, en gardant les effets qu'il avoit rapportés.

Vous favez, Monfieur, que la Laguna n'eit pas fituée fur le bord de l'Amazone, mais à quelques liettes en remontant le Guallaga, l'ine des rivieres qui grofiffent ce fleuve de leurs eaux. Joachim congédié par le fieur $R$....., n'ent garde d'aller rechercher à la Laguna fa maitrefe qu'il croyoit morte. Il retourna droit à Quito; ce $\mathrm{P}$ ivegre elt perdu pour elle \& pour moi. Vous n'imagineriez pas quelle raifon $m^{2}$ depuis alléguée le fieur $R$... pour fe difculper d'avoir renvoyé un domeftique fidèle $2 x$ qui nous étoit fr nécelfüre. "Je craígnois, me dit-il, " qu'il ne m’affaffnât ". Qui pouvoit, lui répliquaije, vous donner un tel foupçon d'in homme dont vous connoifiez le zèle \& la ficélité, \& qui avoit navigué avec vous pendant long-tems? Si vouls craigniez qu'il ne yous vît de mauvais oil, \& qu'il ne vous imputât la mort de fa maitreffe, que ne l'envoyiez-vous à M. de Grandmaifon qui le réclamoie \& qui n'étoit pas loin de vous? Que ne le faifiez-vous. au moins mettre aux fers? Vous étiez chez le Gouverneur d'Onaguas qui vous auroit prêté main-forte J'ai de tout cela un certificat de M. d'Alibanel, Com. mandant d'Oyapok, en préience de qui je fis ces reproches au fieur $R$. ...., \&.ce certificat eft légalifé par le Juge de Cayenne.

Pendant ce tems Madame Godin, avec le canot \& les Indiens d'Andoas, étoit arrivée à la Laguza ou elle fut reçue avec toute l'affabilité poffible par le Doteur Roméro, nouveausupérieur des mifions, quiry par fes bons tratiemens pendant environ fix femaines. qu’elle y féjourna, n’oublia: rien pour rétablir fa fanté fort altérée, \& pom la diftrate du fouvenir de fes malhents, Le premier foinduDoctent? nneto fut 


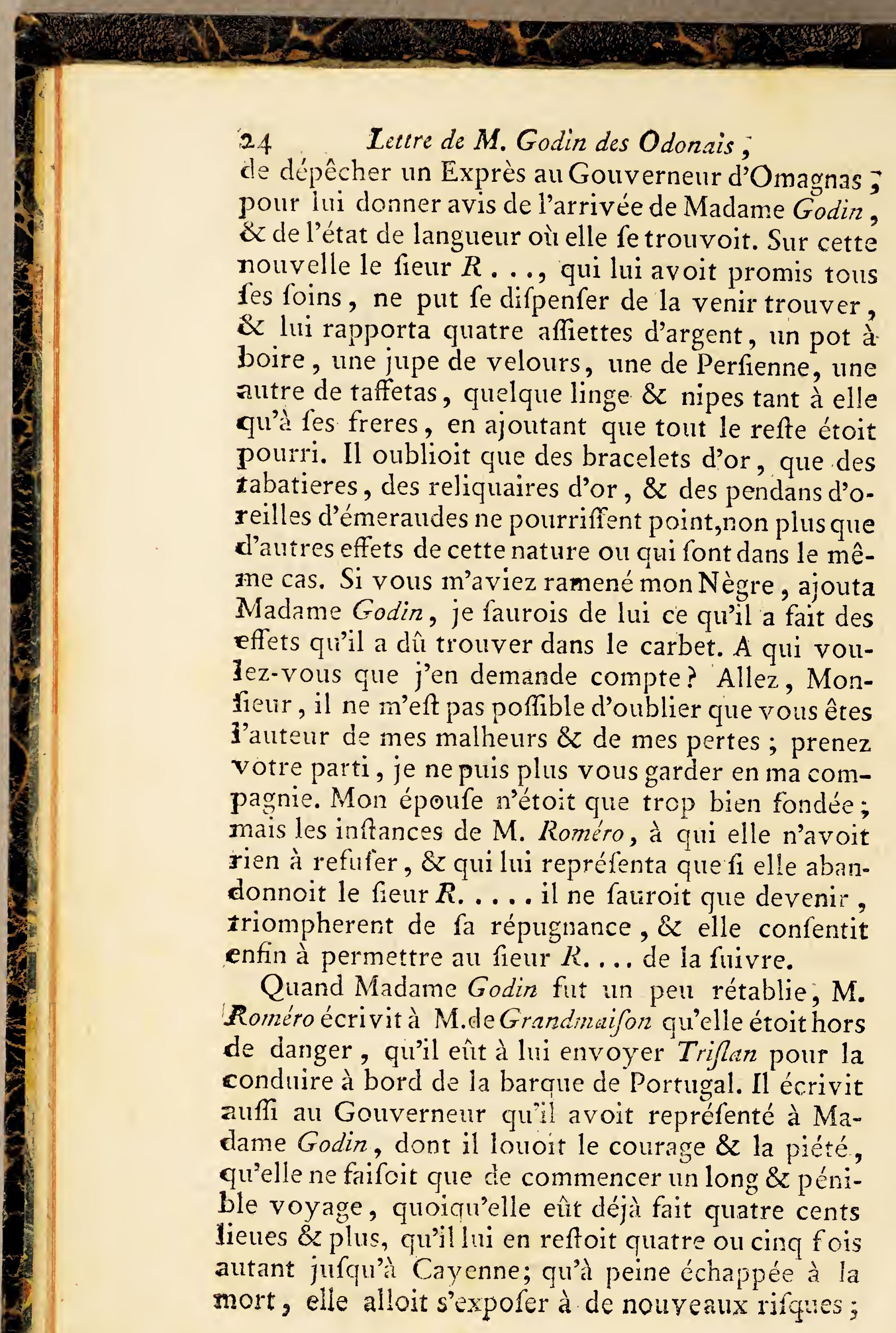




\section{'à de la Condaminé.}

qu'il lui avoit offert de la faire reconduire en toute fûreté à Riobamba fa réfidence; mais qu'elle lui a voit répondu qu'elle étoit étonnée de la propofition qu'il lui faifoit; que Dieu l'avoit préfervée feule des périls où tous les fiens avoient fuccombé; qu'elle n'avoit d'autre defir que de joindre fon mari; qu'elle ne s'étoit mife en route qu'à cette intention, \& qu'elle croiroit contrarier les vues de la. Wrovidence, en rendant inutile l'affiftance qu'elle avoit reçue de fes deux chers Indiens \& de leurs femmes, ainf quie tous les fecours que lui-même; M. Romero, lui avoit prodigués; qu'elle leur devoit la vie à tous, \& que Dieu feul pouvoit les récompenfer. Ma femme m'a toujours été chère; mais de pareils fentiments mont fait ajouter le refpect à la tendreffe. Triftan n'arrivant point; M. Roméro, après l'avoir attendu inutilement, arma un canoí, $\&$ donna ordre de conduire Madame Godin à bord du bâtiment du Roi de Portugal, fans s'arrêter en aucun endroit. Ce fut alors que le Gouverneur d'Omaguas, fachant qu'elle defcendoit le fleuve, \& ne devoit mettre à terre nulle part, envoya un canot à fa rencontre avec quelques rafraichifemens.

Le Commandant Portugais, $M$. de Rebello, en ayant eu avis, fit armer une pirogue commandée par deux de fes foldats, \& munie de provifions, avec ordre d'aller au devant de Madame Gedin. Ils la joignirent au village de Pévas. Cet Officier, pour remplir plus exactement encore les ordres du Roi fon maitre, fit remonter avec beaucoup de peine fon bâtiment, en doublant les rameurs, jufqu'à la Miffion Efpagnole de Loréro, oì il la recut à fon bord. Elle m'a affuré que depuis ce moment jufqu'à Oyapok, pendant le cour's d'environ mille lienes, rien ne lui manqua pour les commodités les plus recherchées, ni pour la chère la plus délicate, à quoi elle ne pouvoit s'attendre, ce qui n'a peut- 


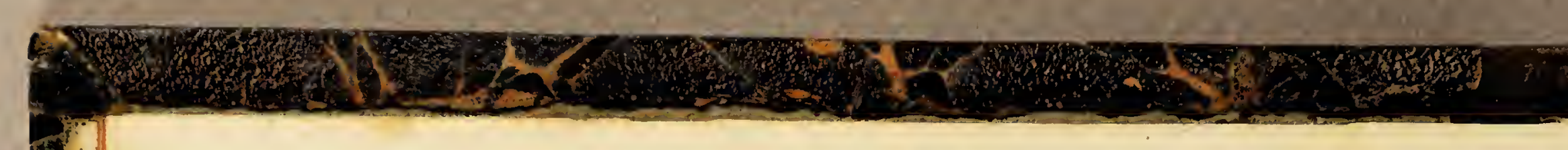

20

Leirre de $M$. Godin des Odonais;

être pas d'exemple'dans une pareille navigation provifions de vins \& de liqueurs pour elle dont elle ne fait aucun ulage, abondance de gibier $\&$ de poiffon, au moyen de deux canots qui prenoient les de. vants de la galiote. M. le Gouverneur du Parì avoit envoyé des ordres dans la plupart des portes, 2 de souveaux rafraîchiffemens.

J'oubliois dé vous dire que les fouffrances de mon époufe n'étoient pas finies; qu'elle avoit le pouce d'une main en fort mauvais état Les épines qui y étoient entrées dans le bois, \& qu'on n'avoit encore pu extirper, avoient formé un abcès, le tendon \& l'os même étoient endommagés. On parloit de Iui couper le pouce. Cependant ì force de foins 8 de topiques, elle en fut quitte pour les douleurs de lopération par laquelle on lui tira quelques efquilles. à San-Pablo, \&c pour la perte du mouvement de l'articulation du pouce. La galiote continua fa route à la fortereffe de Curupa, que vous connoiffez à foixante lieues environ au-deffus du Parà. M. de Martel, Chevalier de l'Ordre de Chrif, Major de la garnifon du Parà, y arriva le lendemain par ordre du Gouverneur pour prendre le commandement de la galiote, \& conduire Madame Godin au fort. d'Oyapok. Peu après le débouquement du fleuve, dans un endroit de la côte où les courans font trèsviolens (I), il perdit une de fes anchres; \& comme il eût été imprudent de s'expofer avec une feule, il envoya fa chaloupe à Oyapok chercher du fecours, qui lui fut auffi-tôt envoyé. A cette nouvelle je fortis du port d'Oyapok fur une galiotte qui mappartenoit, avec laquelle jallai croifer fur la côte à la rencontre du bâtiment que jatteignis, le quatrieme jour, par le travers de Mayacaré;

(i) A l'embouchure d'une rivière, dont le nom Indien, corrempu à Cayenne, eft le Carapa pourr. 


\section{a $M$. de la Condamine.}

\&r ce fut fur fon bord qu'après vingt ans d'abfence, "d'alarmes, de traverfes \& de malheurs réciproques, je rejoignis une époufe chérie que je ne me flattois plus de revoir. J'oubliai dans fes embraffemens la perte des fruits de notre union dont je me félicite même, puifqu'une mort prématurée les a préfervés du fort funefte qui les attendoit ainfi que leurs oncles dans les bois de Canelos, fous les yeux de leur mere, qui n'auroit fûrement pas furvécu à ce fpectacle (I). Nous mouillâmes à Oyapok le 22 Juillet 1770. Je trouvai en M. de Martel un Officier auffi difingué par fes connoiffances que par les avantages extérieurs. Il poffède prefque toutes les langues de l'Europe, la latine même fort bien; \& pourroit briller fur un plus grand théatre que le Parà. Il eft d'origine Françoife, de l'illuftre famille dont il porte le nom. J'eus le plaifir de le pofféder pendant guinze jours. à Oyapok, où M. de Fiedmond, Gouverneur de Cayenne, à qui le Commandant d'Oyapok donna avis de fon arrivé par un Exprès, dépêcha aufl-tôt un batean arec des rafraichiffemens. On donna au: bâtiment Portugais une carène dont il avoit befoin, $\&$ une voilure propre à remonter la côte contre les courans. M. le Commandant d'Oyapok donna à M. de Maŕtel un pilote-côtier pour l'accompagner jufqu'à la frontière. Je me propofois de le conduire jufques - là dans ma galiote; mais il ne me permit pas de le fuivre plus loin cue le cap d'Orange. Je le quittai avec tous les fentimens que m'avoient infpirés ainfi qu'à mon époufe les procédés nobles $\&$ les attentions fines qu'elle \& moi avions éprou-

(i) Ma derniere filic étoit morte de la petite vérole dix-hnir mois avant le départ de fa mese, de Riobamba, âgée de dixhuit a dix-neuf ans. Elle étoit née trois mois après mon départ de la Prorince de Quito: \&receft par une de vos lettres de paris quej'en reçus la nouvelle à Cayenne en 1752 . 


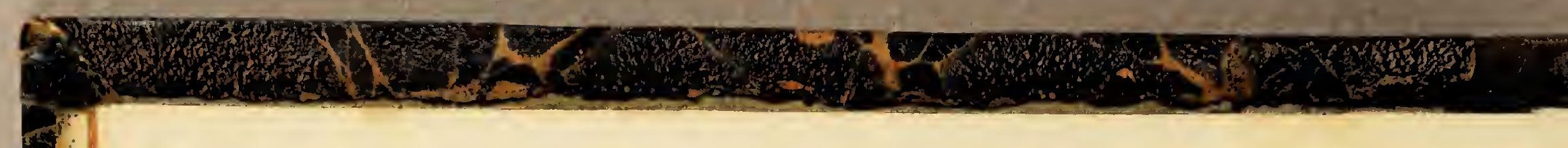

48

Leture de M. Godin des Odonais,

vés de cet Officier \& de fa généreufe nation. I'y: avois été préparé dès mon précédent voyagge.

I'aurois dû vous dire plutôt, qu'en défcendant I'Amazone l'année $\mathbf{I} 749$, faus autre recommendation pour les Portugais, que le fouvenir de la nouvelle que vous aviez répandue à votre paffage en 743, qu'un de vos Compagnons de voyage prendroit la même route que vous; je fus reçu dans tous les établiffemens du Portugal par les Miffionnaires \& tous les Commandans des. Forts, avec toute l'affabilité poffible. J'avois fait en paffant à San-Pablo l'acquifition d'un canot, fur lequel j'avois defcenfu le fleuve jufqu'au Fort de Curupa, d'où j'écrivis au Gouverneur du Grand Parà, M. François Mendoz̧a Gorjaó, pour lui faire part de mon arrivée, \& lui demander la permiffion de paffer de Curupa à Cayenne, où je comptois me rendre en droiture. Il mho. nora d'une réponfe fi polie, que je n'héfitai pas à quitter ma route, \& à prendre un très-long détour. pour l'aller remercier, \& lui rendre mes devoirs. Il me reçıt à bras ouverts, me logea, ne permit pas que j'euffe d'autre table que la fienne, me rea. tint huit jours, \& ne voulut pas me laiffer partive avant qu'il ne partît lui-même pour Saint-Louis de Maranaô, oì il alloit faire fa tournée. Après fon départ je remontai àCurupa avec mon canot efcortédun autre plus grand que m'avoit donné le Commandant de ce For t pour defcendre au Parà, qui, comme vouts l'avez remarqué,eft fur une grande rivière qu'on a pris. mal à propos pour le bras droit de l'A mazone, avec laquelle la riviere de Parà communique par un canal naturel creufé par les marées, qu'on nomme Tagipuru. Je trouvai à Curupa une grande pirogue qui m'attendoit, armée par ordre du Gouverneur de Parà, commandée par un Sergent de la Garnifon, \& a amée de quatorze rames, pour me conduire à Cayenne, où je me rendis par Macapa, en cotoyant la rive 


\section{M. de ta Condanine.}

gauche de l'Amazone, jufqu'à fon embouchure, fans faire comme vous le tour de la grande Ifle de Joanes ou de Marajo. Après un pareil traitement reçu fans recommandation expreffe, à quoi ne devois-je pas m'attendre depuis que $S . M . T$. F. avoit daigné donner des ordres précis pour expédier un bâtiment jufqu'à la frontiere de fes Etats, \& deftiné recevoir ma famille pour la tranfporterà Cayenne ?

Je reviens à mon récit.Après avoir pris congé de M. de Martel fur.le cap d'Orange avec toutes les démonftrations d'ufage en pareil cas entre les marins je revins à Oyapok d'où je me rendis à Cayenne.

Il ne me manquoit plus que d'avoir un procès que j'ai gagné bien inutilement. Triftan me demandoit le falaire que je lui avoit promis de 60 livres par mois. J'ofiris de lui payer dix-huit mois, qui étoient le tems au plus qu'auroit duré fon voyage s'il eût exécuté fa commiffion. Un Arrêt du Coníil Supérieur de Cayenne, du 7 Janvier dernier, l'a condamné à me rendre compte de fept à huit mille francs d'effets que je lui avois remis, déduction faite de 1080 livres que je lui offrois pour dix - huit mois de falaire entre nous convenu. Mais ce malheureux, après avoir abufé de ma confiance, après avoir cauféla mort de huit perfonnes, en comptant I'Indien noyé \& tous les malheurs de mon époufe, après avoir diffipé tout le produit des effets que je lui avois confiés, reftoit infolvable; \& je n'ai pas cru devoir augmenter mes pertes en le nourriffant en prifon.

Je crois, Monfieur, avoir fatisfait à ce que vous defiriez. Les détails où je viens d'entrer m'ont beaulcoup coûté, en me rappellant de douloureux fouvenirs. Le procès contre Triftan \& les maladies de ma femme depuis fon arrivée à Cayenne, qui n’étoient que la fuite de ce qu'elle avoit fouffert, ne m'ont pas permis de l'expofer plutôt quẹ cẹtte an- 


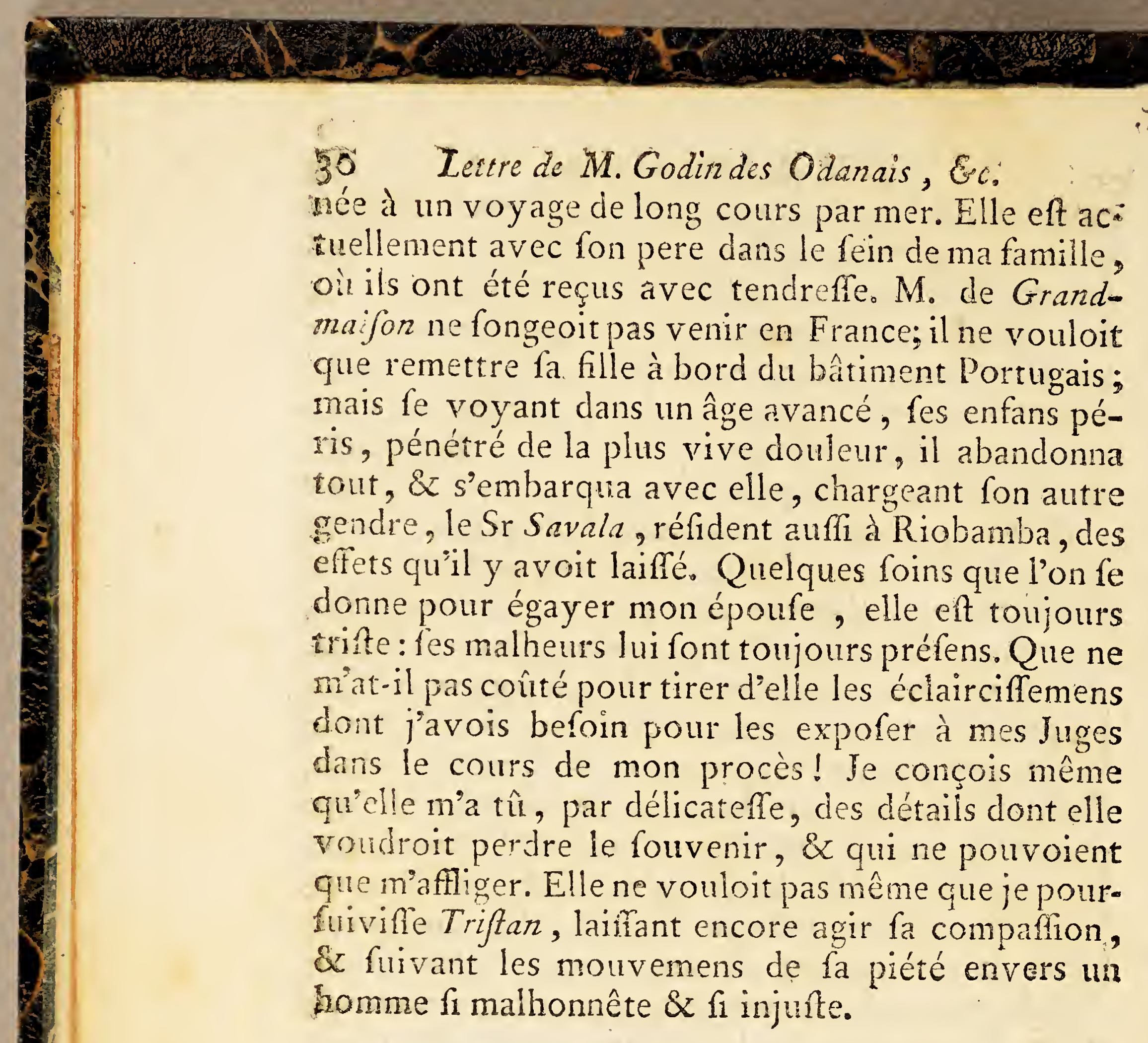

\section{EIN}







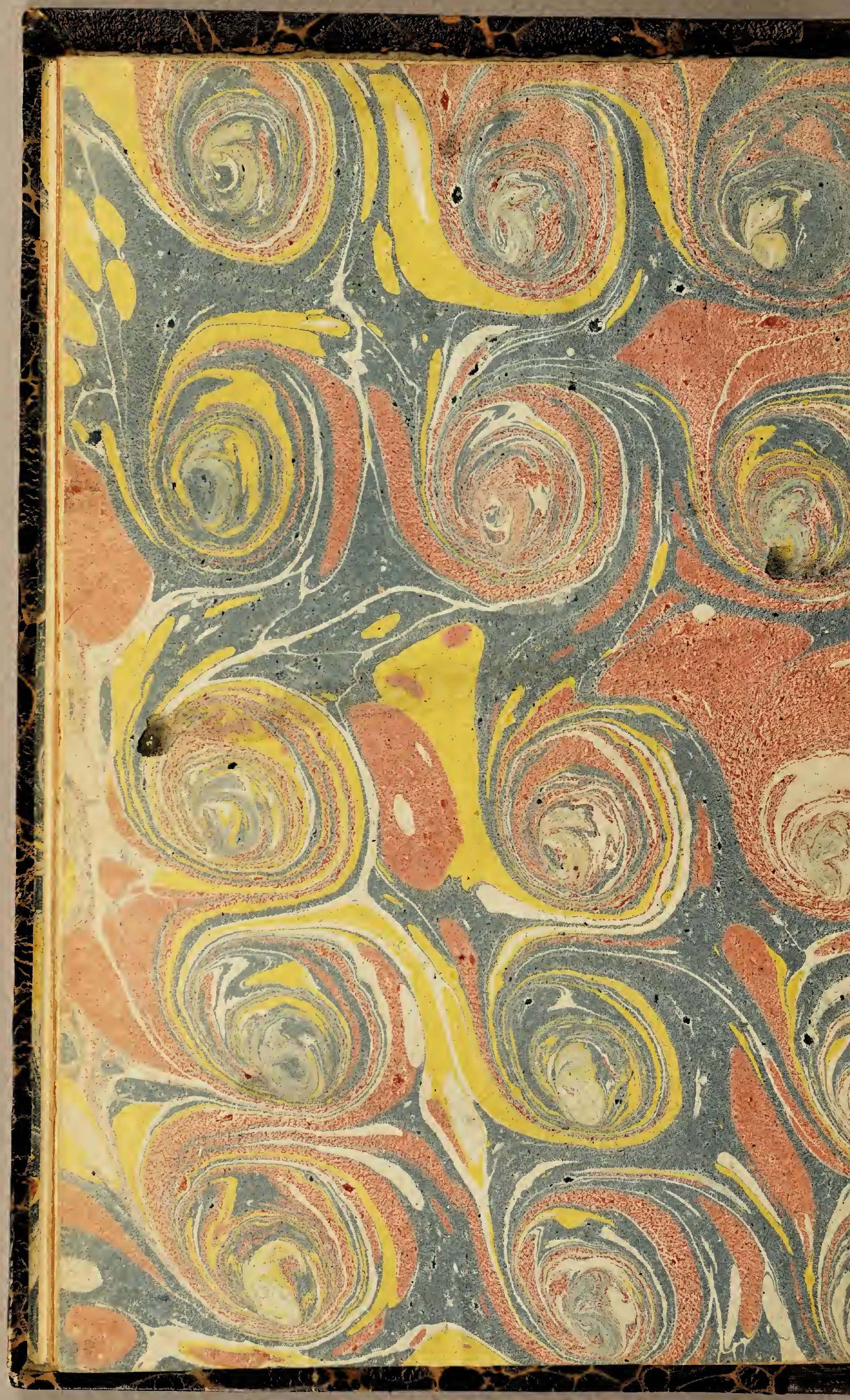


$x^{2}, x^{2}$

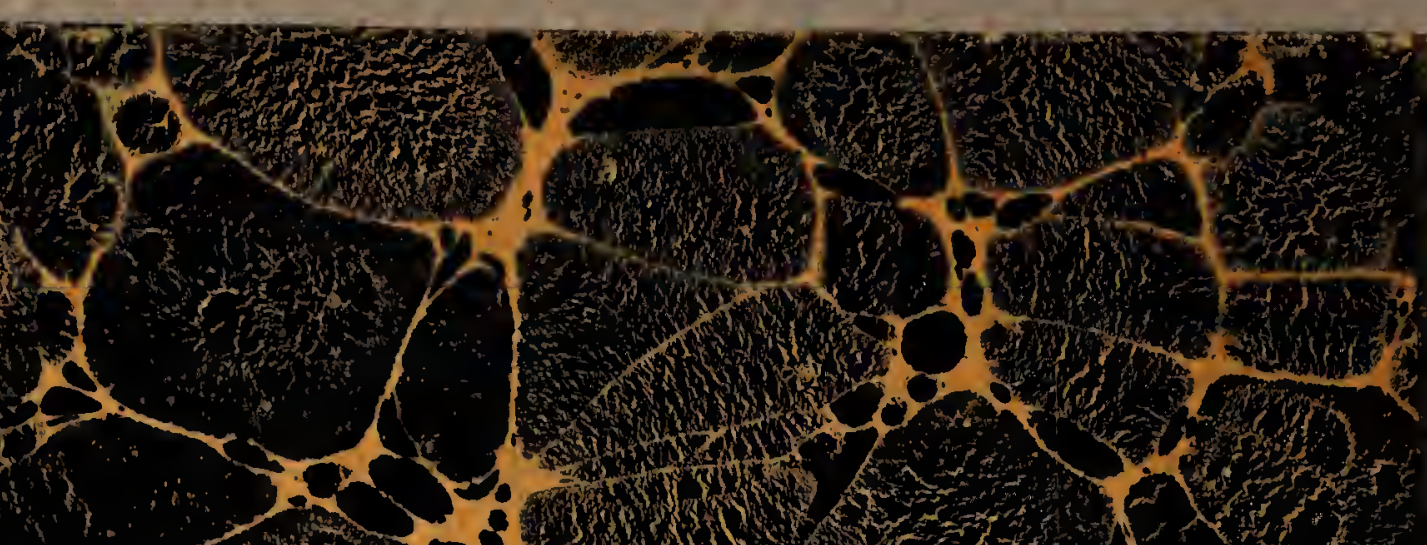

(5.

noy r r 7. r. 5. - 150.20
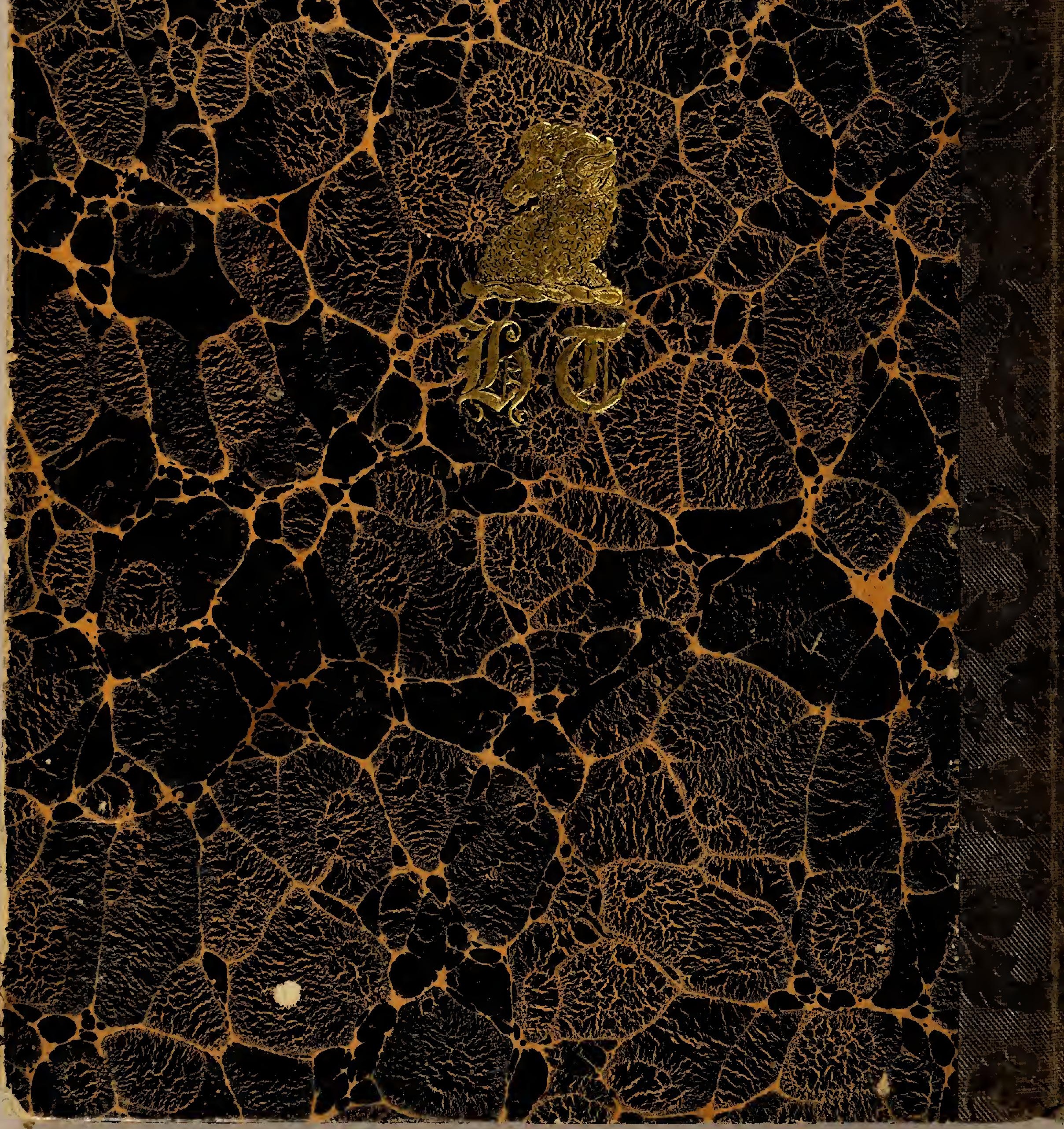